RESEARCH REPORT

\title{
Trends in the sex ratio of California births, 1960-1996
}

\author{
Daniel Smith, Julie Von Behren
}

J Epidemiol Community Health 2005;59:1047-1053. doi: 10.1136/jech.2005.036970

See end of article for authors' affiliations

Correspondence to:

Dr D Smith, Environmental

Health Investigations

Branch, 850 Marina Bay

Parkway, Bldg P, 3rd

Floor, Richmond, CA

94804-6403, USA;

DSmith2@dhs.ca.gov

Accepted for publication 20 July 2005
Study objective: The male sex ratio at birth (or the proportion of male births in a population) has been suggested as a sentinel environmental health indicator. Usually around $51 \%$, the proportion may be dramatically decreased in offspring of persons with chemical exposures. Recent publications from the USA and elsewhere have noted a small but apparently declining male birth proportion, suggesting the effect of some environmental exposures. This paper sought to examine these trends more closely in California's large and diverse population.

Design: Using computerised birth certificate data, time trends were examined by multivariate linear and spline regression, controlling for demographic factors.

Setting: California.

Participants: About 15 million births from 1960 to 1996.

Main results: In the raw data, the male birth proportion is indeed declining. However, during this period, there were also shifts in demographics that influence the sex ratio. Controlling for birth order, parents' age, and race/ethnicity, different trends emerged. White births (which account for over $80 \%$ ) continued to show a statistically significant decline, while other racial groups showed non-statistically significant declines (Japanese, Native American, other), little or no change (black), or an increase (Chinese). Finally, when the white births were dividied into Hispanic and non-Hispanic (possible since 1982), it was found that both white subgroups suggest an increase in male births.

Conclusion: This analysis shows that the decline in male births in California is largely attributable to changes in demographics.
$\mathrm{T}$ he sex ratio of births (the relative number of male and female births) has been suggested as a sentinel indicator of environmental exposures, ${ }^{1}$ that is, an event whose occurrence can serve as a signal that an adverse environmental exposure has occurred. ${ }^{2}$ The sex ratio as we use it in this report, the proportion of births that are male, is usually cited as around 0.515 ( 106 males births to every 100 female), but has been reported to range internationally from 0.503 to $0.517 .^{3}$

The appeal of the sex ratio as a sentinel environmental indicator lies in the fact that (1) it is a comparatively easy statistic to gather in populations, and (2) it is reportedly changed, sometimes dramatically so, in births from people with a variety of toxic exposures and occupations. ${ }^{4-9}$ Usually, exposures seem to reduce the proportion of male births, but some investigators have reported the opposite or no effect. ${ }^{10}{ }^{11}$

Complicating the issue, several demographic factors are also well known to be associated with the birth sex ratio in the absence of any environmental exposures. Among these are race, ${ }^{12}{ }^{13}$ birth order, ${ }^{14}$ and parent's ages. ${ }^{14}{ }^{15}$

Reports from the USA, Canada, several European countries, and Japan ${ }^{1}{ }^{16}$ have shown declines in male births, while other countries have shown increases. ${ }^{17-20}$ Long term trends in some countries show various shifts. ${ }^{21}{ }^{22}$ Theories put forth to account for the long term trends (in both directions) include changes in diet and nutrition, hormonal changes because of economic and wartime stresses, and improvements in medical care leading to fewer stillbirths (which tend to be male). ${ }^{17}$ 22-24

Davis et al ${ }^{1}$ presented crude data from the USA and Canada from 1970 to 1990 showing a decline in male births in both countries. They pointed out that the change, while on the order of a tenth of a percentage, translates into tens of thousands of fewer male births than expected nationwide. Later studies have shown inconsistencies by race and by region. Nicolich et al ${ }^{15}$ examined US national data from 1964 to 1995, and found an apparent decline in male births among white groups, but an increase among non-white groups. Marcus et $a l^{13}$ analysed US data from 1969 to 1995 by region and race, and similarly noted a decline in male births among the white population and an increase among the black population generally for the nation. An exception to this was the "Pacific" region (not defined, but presumably including California), where the decline was observed in both white and black populations.

Davis et al proposed that the sex ratio might be used for surveillance of environmental exposures in the general population, as the US national decline they noted might be revealing, and was unlikely to be attributable to secular changes in known sex ratio determinants. ${ }^{1}$ Others have questioned the use of the sex ratio as a surveillance tool on a population level. ${ }^{25}$ Davis and colleagues called for further analyses in states and other regions to resolve these issues. Our goal was to examine trends by focusing the analysis on California, where we can extend the time period examined back to 1960, and obtain more detailed demographic data, especially for race, than are available at the national level.

\section{METHODS}

We accessed computerised birth files from the California Department of Health Services' Center for Health Statistics for each year from 1960 to 1996. These files included all California births, and contain data recorded on the birth certificates, including sex of the child, maternal age, paternal age, birth order, and race. The records contained no personal identifiers.

Race of the child was categorised into six groups: white, black, Chinese, Japanese, Native American, and "other". The Native American group included American Indian, Eskimo, and Aleut. The other category included Filipino, Hawaiian, other Pacific Islander, Vietnamese, Korean, and other Asian. The race/ethnicity of the child is generated by the state Office 


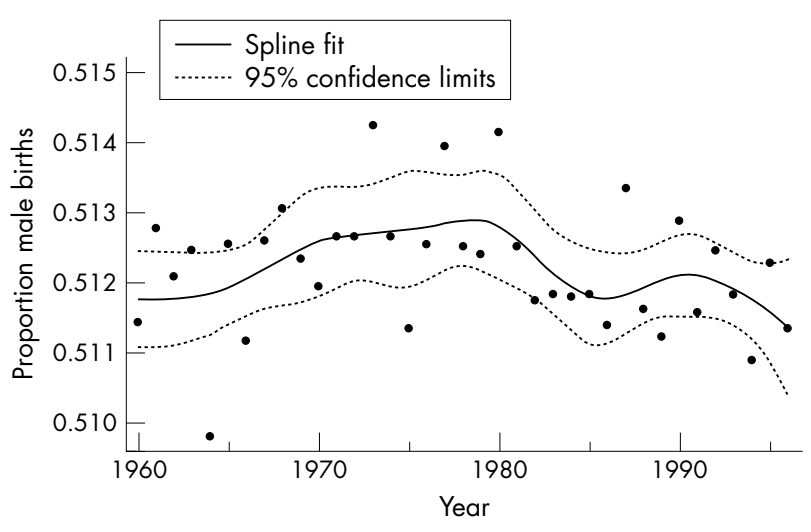

Figure 1 Proportion of male births by year, with spline curve fit, California, 1960-1996.

of Vital Records as a combination of mother's and father's race/ethnicity, based on self report. In most cases, when the mother and father were of different races, the child was coded to the father's race. The exception is black, however, when the child is coded as black if either parent is black. The variable was left missing if race was coded as unknown or refused to state. A recent validation study of California birth certificates showed that race and Hispanic ethnicity had high positive predictive values and sensitivity for all groups except the comparatively small proportion of Native Americans. ${ }^{26}$

The large number of births over this period ( 15.7 million) precluded analysing the data as individual observations. Instead, we compacted the dataset by grouping births into categories of covariates: six categories each of mother's and father's age (less than 17 years, 18-19, 20-24, 25-29, 30-39, and 40 years and over), four categories of birth order (first, second, third, and fourth or more), and six categories of race of the child (white, black, Chinese, Japanese, Native American, and all others). In addition to these racial groups, Hispanic ethnicity for parents is available for the years 1982 to 1996, permitting the further division of white into Hispanic (either or both parents) compared with nonHispanic.

Births with missing, unknown, or decline to state entries for any of the demographic variables were excluded from the multivariate analysis. Missing or unknown mother's age, race of child, and birth order was found on less than $1 \%$ of records. Father's age was missing on $8 \%$ of the total records, but this was largely confined to the years 1966 and 1967, when father's age was not available on any record. Not counting those two years, father's age was missing on $4 \%$ of records. Of the initial 15.7 million births, about 14.4 million $(92 \%)$ had complete information for the multivariate analyses.

We analysed the sex ratio in terms of the proportion of births that were male. Regression analysis used the log of male proportion as the dependent variable, assumed to have a binomial distribution. ${ }^{27}$ Regressions were performed with the procedure "binreg" in Stata (StataCorp, College Station, TX). The regression coefficient for an independent variable gives the change in log male proportion associated with a one unit change in that variable. Exponentiating the regression coefficient provides a multiplier of the male proportion associated with a one unit change, where values greater than one indicate an increasing proportion, and less than one, a decrease. These exponentiated regression coefficients

Table 1 Number of births and the proportion male, by parent's age, child's race, and birth order, California, 1960-1996

\begin{tabular}{|c|c|c|c|c|}
\hline & \multicolumn{2}{|c|}{ Number of births } & \multirow[b]{2}{*}{ Number of male births } & \multirow[b]{2}{*}{ Male proportion } \\
\hline & Number & (\%) & & \\
\hline \multicolumn{5}{|l|}{ Mother's age } \\
\hline$\leqslant 17$ & 761830 & (5) & 390858 & 0.5131 \\
\hline $18-19$ & 1395825 & (9) & 715878 & 0.5129 \\
\hline $20-24$ & 4865528 & (31) & 2490977 & 0.5120 \\
\hline $25-29$ & 4517203 & (29) & 2314573 & 0.5124 \\
\hline $30-39$ & 3904077 & (25) & 1997962 & 0.5118 \\
\hline$\geqslant 40$ & 238260 & (2) & 121709 & 0.5108 \\
\hline Missing & 4212 & $(<1)$ & 2168 & 0.5147 \\
\hline Total & 15686935 & (100) & 8034125 & 0.5122 \\
\hline \multicolumn{5}{|l|}{ Father's age } \\
\hline$\leqslant 17$ & 152092 & (1) & 78186 & 0.5141 \\
\hline $18-19$ & 554497 & (4) & 284423 & 0.5129 \\
\hline $20-24$ & 3406113 & (22) & 1747155 & 0.5129 \\
\hline $25-29$ & 4315299 & (28) & 2211308 & 0.5124 \\
\hline $30-39$ & 4989680 & (32) & 2553694 & 0.5118 \\
\hline$\geqslant 40$ & 999949 & (6) & 510949 & 0.5110 \\
\hline Missing & 1269305 & (8) & 648410 & 0.5108 \\
\hline Total & 15686935 & (100) & 8034125 & 0.5122 \\
\hline \multicolumn{5}{|l|}{ Race } \\
\hline White & 12814218 & (82) & 6565241 & 0.5123 \\
\hline Black & 1490255 & (9) & 756711 & 0.5078 \\
\hline Chinese & 226049 & (1) & 116968 & 0.5174 \\
\hline Japanese & 140135 & (1) & 71937 & 0.5133 \\
\hline Native American & 132150 & (1) & 67164 & 0.5082 \\
\hline All others & 825707 & (5) & 426145 & 0.5161 \\
\hline Missing & 58421 & $(<1)$ & 29959 & 0.5128 \\
\hline Total & 15686935 & (100) & 8034125 & 0.5122 \\
\hline \multicolumn{5}{|l|}{ Birth order } \\
\hline First & 6075128 & (39) & 3121072 & 0.5137 \\
\hline Second & 4644454 & (30) & 2377414 & 0.5119 \\
\hline Third & 2509813 & (16) & 1284654 & 0.5119 \\
\hline Fourth or higher & 2387272 & (15) & 1215114 & 0.5090 \\
\hline Missing & 70268 & $(<1)$ & 35871 & 0.5105 \\
\hline Total & 15686935 & (100) & 8034125 & 0.5122 \\
\hline
\end{tabular}



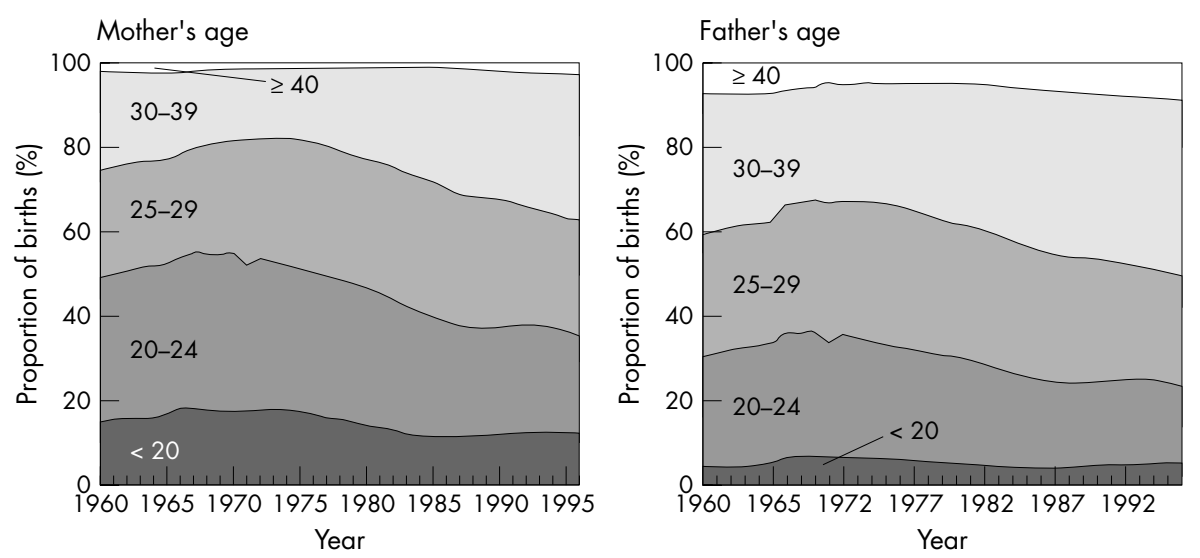

Figure 2 Proportion of births by mother's and father's age, child's birth order, and race by year, California, 1960-1996.
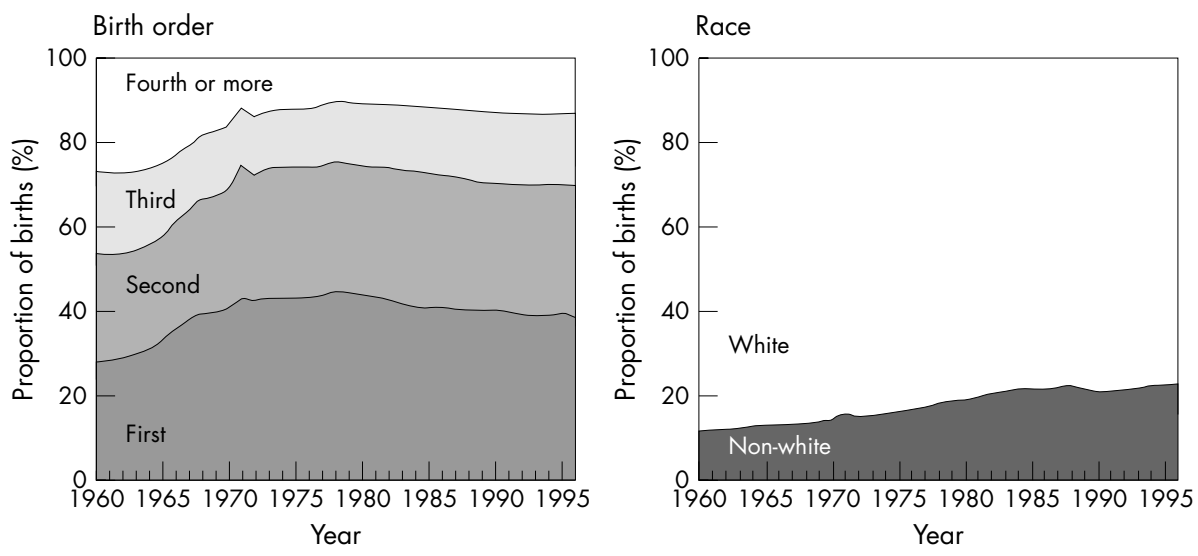

are given in the tables of results. Two sided 95\% confidence intervals are provided throughout.

To evaluate trends in the male birth proportion over time, the main independent variable of interest was the year of birth. We modelled time in three ways: as a linear term (year), as a quadratic (year + year $^{2}$ ), and as a flexible cubic spline, with join points at five year intervals. ${ }^{28}$ The fits of the different models were compared using the Akaike information criterion (AIC). ${ }^{29}$

To control for confounding effects of changes in demographic characteristics, a multivariate regression analysis included child's race/ethnicity, birth order, and parents' ages. We assessed the statistical association of these covariates

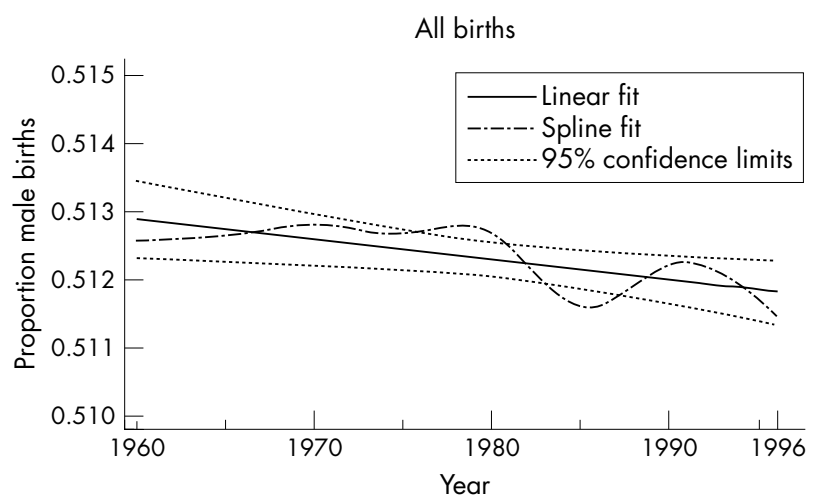

Figure 3 Proportion of male births by year, spline and linear multiple regressions, all births, adjusted for birth order, race, and parents' ages, California, 1960-1996. with male proportion by a likelihood ratio test of the model with the covariate represented by indicator terms standing for its categories compared with a model omitting all indicator terms from the model. ${ }^{29}$ We produced standardised (adjusted) male proportions from the fitted model with the covariates held at fixed values, namely the proportions of total births in each category. ${ }^{30}$

\section{RESULTS}

From 1960 to 1996, over 15 million births occurred in California. The number of births per year grew from as few as 300000 per year in the early 1970s to twice that number in the late 1980 s.

The crude (unadjusted) California male birth proportion itself fluctuated between about 0.510 to 0.514 per year (fig 1 ), with the average over this entire period 0.5122 (table 1). This can be compared with a cited value for the USA as a whole of 0.5123 for 1958-1997. ${ }^{3}$ A smoothing spline through these data suggests first a rising then falling trend over this span, although the range of this trend is smaller than the variation in values year to year (fig 1). This unadjusted spline regression depicts an overall decline in the male birth proportion from 0.5118 in 1960 to 0.5114 in 1996.

In the crude data, increasing mother's and father's age and birth order seem to decrease the male birth proportion (table 1). Also, the various racial groups show differing proportions, higher for Asian births, and lower for black births and Native Americans. Besides having their own associations with the sex ratio, the distributions of these demographic characteristics in the California population have changed over this 37 year period (fig 2). The proportion of children born to mothers 30 years of age or older increased from $25 \%$ to $37 \%$, and fathers 30 or older increased from 
Table 2 Change in male birth proportion with year, California, 1960-1996. Models control for race, birth order, and parents' age, differing only in their representation of year

\begin{tabular}{|c|c|c|c|}
\hline & Linear* (year) & Quadratic (year + year ${ }^{2}$ ) & $\begin{array}{l}\text { Spline (join points at five year } \\
\text { intervals) }\end{array}$ \\
\hline AIC & 100474 & 100476 & 100480 \\
\hline $\begin{array}{l}\text { Change in male proportion } \\
\text { Likelihood ratio test }\end{array}$ & $\begin{array}{l}0.9974 \dagger(0.9956 \text { to } 0.9991) \\
p=0.004\end{array}$ & $\begin{array}{l}0.9974(0.9956 \text { to } 0.9991) \\
p=0.01\end{array}$ & $\begin{array}{l}0.9974(0.9950 \text { to } 0.9998) \\
p=0.03\end{array}$ \\
\hline \multicolumn{4}{|l|}{ Mother's age } \\
\hline$\leqslant 17$ & 1.0005 (0.9975 to 1.0035$)$ & & \\
\hline $18-19$ & $1.0006(0.9985$ to 1.0027$)$ & & \\
\hline $20-24$ & 1 (reference category) & & \\
\hline $25-29$ & $1.0024(1.0010$ to 1.0039$)$ & & \\
\hline $30-39$ & 1.0031 (1.0013 to 1.0049$)$ & & \\
\hline$\geqslant 40$ years & $1.0035(0.9988$ to 1.0081$)$ & & \\
\hline Likelihood ratio test & $p=0.02$ & & \\
\hline \multicolumn{4}{|l|}{ Father's age } \\
\hline$\leqslant 17$ & $1.0014(0.9961$ to 1.0068$)$ & & \\
\hline $18-19$ & 0.9994 (0.9964 to 1.0024$)$ & & \\
\hline $20-24$ & 1 (reference category) & & \\
\hline $25-29$ & $0.9987(0.9971$ to 1.0002$)$ & & \\
\hline $30-39$ & $0.9970(0.9952$ to 0.9988$)$ & & \\
\hline$\geqslant 40$ & 0.9965 (0.9938 to 0.9991$)$ & & \\
\hline \multirow{2}{*}{\multicolumn{4}{|c|}{$\begin{array}{l}\text { Likelinood ratio fest } \\
\text { Birth order }\end{array}$}} \\
\hline & & & \\
\hline First & 1 (reference category) & & \\
\hline Second & 0.9964 (0.9952 to 0.9977$)$ & & \\
\hline Third & $0.9962(0.9946$ to 0.9978$)$ & & \\
\hline Fourth or higher & 0.9906 (0.9889 to 0.9923$)$ & & \\
\hline Likelihood ratio test & $p<0.001$ & & \\
\hline \multicolumn{4}{|l|}{ Race/ethnicity } \\
\hline White & 1 (reference category) & & \\
\hline Black & 0.9915 (0.9898 to 0.9933$)$ & & \\
\hline Chinese & 1.0095 (1.0054 to 1.0137$)$ & & \\
\hline Japanese & $1.0015(0.9962$ to 1.0068$)$ & & \\
\hline Native American & $0.9922(0.9867$ to 0.9978$)$ & & \\
\hline Other & $1.0083(1.0060$ to 1.0106$)$ & & \\
\hline Likelihood ratio test & $p<0.001$ & & \\
\hline
\end{tabular}

about $40 \%$ to $50 \%$. At the same time, first borns increased from $28 \%$ to $38 \%$. Finally, the proportion of births of races other than white doubled, from $11 \%$ to $22 \%$. These characteristics are also correlated with each other: mothers' and fathers' ages have a rank correlation ${ }^{31}$ of 0.7 , and mother's age and birth order 0.4. Furthermore, birth order and parents' age differ by race: Chinese and Japanese parents tend to be older than white parents; black and Native American parents younger. Therefore, as each of these characteristics may influence the sex ratio, a complete assessment of the trend in sex ratio must control for these factors.

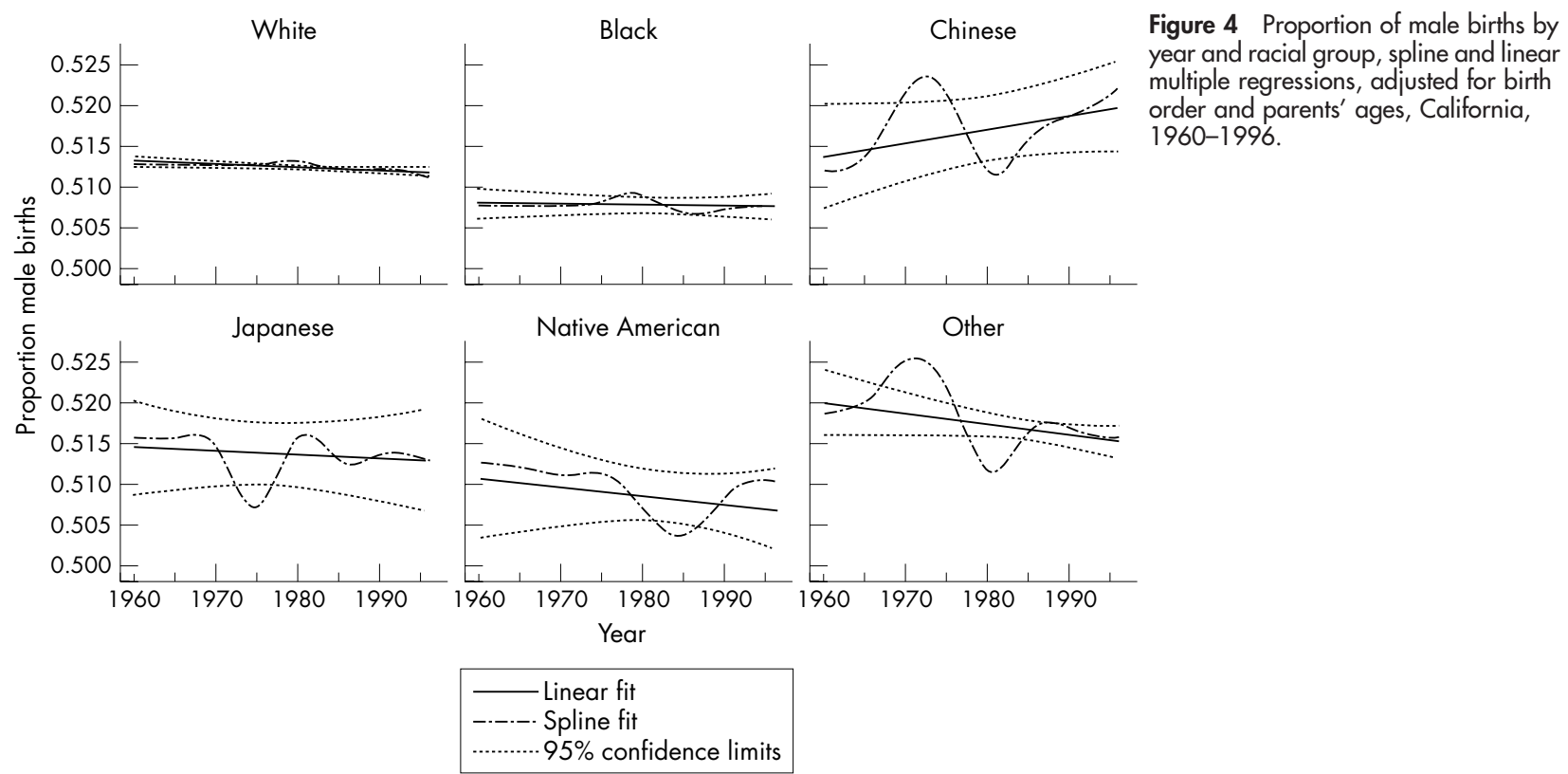


Table 3 Change in male birth proportion, by race, from linear model for year, controlling for birth order and parents' age, California, 1960-1996

\begin{tabular}{lll}
\hline & Change in male proportion & Likelihood ratio test \\
\hline White & $0.9972^{*}(0.9953$ to 0.9992$) \ddagger$ & $\mathrm{p}=0.005$ \\
Black & $0.9990(0.9929$ to 1.0050$)$ & $\mathrm{p}=0.73$ \\
Chinese & $1.0120(0.9946$ to 1.0297$)$ & $\mathrm{p}=0.18$ \\
Japanese & $0.9970(0.9789$ to 1.0155$)$ & $\mathrm{p}=0.75$ \\
Native American & $0.9929(0.9722$ to 1.0141$)$ & $\mathrm{p}=0.51$ \\
All other & $0.9909(0.9807$ to 1.0014$)$ & $\mathrm{p}=0.08$ \\
Hispanic white & $1.0012 \dagger(0.9972$ to 1.0052$)$ & $\mathrm{p}=0.55$ \\
Non-Hispanic white & $1.0016+(0.9974$ to 1.0058$)$ & $\mathrm{p}=0.45$ \\
\hline
\end{tabular}

*Change in male birth proportion over time represents the ratio of the fitted 1996 proportion to the 1960 proportion. †For Hispanic and non-Hispanic births, the change in male proportion is given only for the 15 year span, 1982-1996. $\$ 95 \%$ confidence intervals.

Multivariate analyses of the male birth proportion controlling for these factors (table 2) resulted in an estimated decrease over this time span of 0.9974 (that is, to $99.74 \%$ of its initial value), regardless of whether birth year was treated as a linear term, quadratic, or spline, although the confidence intervals differ somewhat. The AIC criterion favours the linear model. The standardised spline and linear fit lines (from the models in table 2, holding covariates at their population average values) are shown in figure 3.

As expected, the demographic covariates are themselves statistically significant predictors of birth proportions (table 2). For the sake of brevity, table 2 shows the covariate terms only for the linear model; the coefficients of the covariate terms for the other models are identical to the fourth decimal place. Mother's age, father's age, and birth order (adjusted for the presence of the others) all had p values less than 0.05 . Mother's and father's ages showed trends, but unlike the crude analysis, the trends are in the opposite direction: increasing male births with older mothers, decreasing with older fathers. The model fit was improved when both these terms were modelled as continuous linear terms (not shown) compared with the categories in table 2.

Among the race/ethnic groups, black and Native Americans had significantly fewer male births than white, while Chinese and the "other" (primarily Asian) category had more. The Japanese male proportion was not significantly different than the white population.

As different race/ethnicity groups have different baseline sex ratios, and previous US studies have shown differing trends by race, we created adjusted spline and linear fit

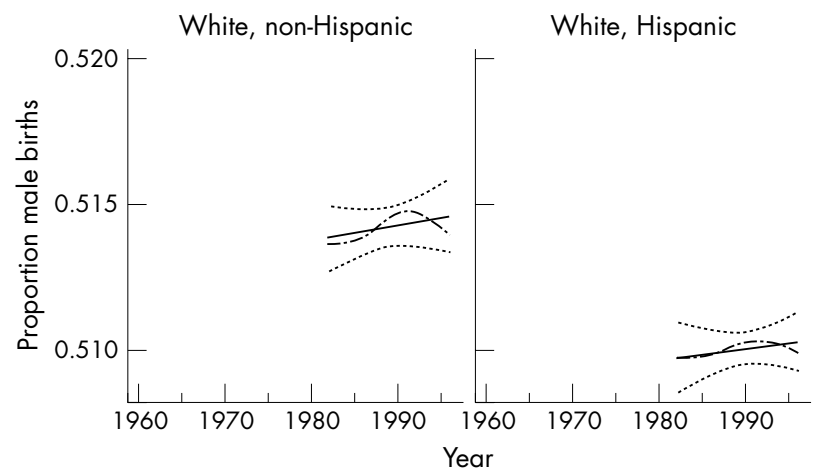

\begin{tabular}{|l|}
\hline Linear fit \\
-.-.-Spline fit \\
…..... 95\% confidence limits
\end{tabular}

Figure 5 Proportion of male births by year for Hispanic and nonHispanic white subgroups, spline and linear multiple regressions, adjusted for birth order and parents' ages, California, 1982-1996. analysis for each race group in figure 4 (standardising on parent's age and birth order, as above), and present the linear regression results in table 3. Again for brevity, the coefficients for parents' age and birth order are not shown for each race group, but generally agree with those in table 2 . Generally, most racial groups show a decline in male birth proportion, however the results are not consistent. Among the nearly 12 million white births, the decline is 0.9972 (95\% confidence interval 0.9953 to 0.9992 ), the only result significant at the traditional level. The point estimates for the smaller Japanese, Native American, and other groups are somewhat lower, but their wide confidence intervals do not preclude an increase in male proportion as well. The Chinese births suggest an increase (although not statistically significant), and the black births show little evidence of an effect.

The white births contain a sizable proportion of births classified as Hispanic. Separating the white births into Hispanic and non-Hispanic is only possible since 1982, when a Hispanic code was introduced. Since 1982, the proportion of white births classified as Hispanic has been rising in California, from $42 \%$ in 1982 to $63 \%$ in 1996. As the black and Native American groups previously noted (table 2), the Hispanic white subgroup had significantly fewer male births than the non-Hispanic white subgroup $(0.9920,95 \%$ confidence interval 0.9903 to 0.9937 ).

To see if the general downward trend among the white population combined since 1960 held for Hispanic and nonHispanic births since 1982, we repeated the analysis for each separately over the shorter 15 year 1982-1996 period (last two rows of table 3). In contrast with the trend for the white groups combined (fig 4), neither white subgroup showed a decrease in male birth proportion over the 15 year span (fig 5). Their increases, 1.0012 for Hispanic and 1.0016 for non-Hispanic, although not statistically significant, are about the same magnitude in the opposite direction as the decrease apparent among the white popuation combined for the same time span.

\section{DISCUSSION}

The overall proportion of male births in California declined slightly over the 37 year time period examined. Using the male birth proportion of 0.5114 from 1960, and assuming about 550000 births per year in recent years, the crude, unadjusted decline translates to a reduction of 730 male births per year, or 1.3 fewer males per 1000 births (95\% confidence limit 0.4 to $2.2 / 1000$ ). This is comparable to the estimate of Davis et al of 1 per 1000 births nationwide. ${ }^{1}$

However, the decline is not consistent across individual race groups. The white population ( $82 \%$ of births) is the only group for which a decline is statistically significant. The black population (which accounted for $9 \%$ of births during this period) do not show this decline, confirming the findings of Marcus et al ${ }^{13}$ and Nicolich et al. ${ }^{15}$ 


\section{What this paper adds}

What is already known on this subject?

The proportion of births that are male is usually around $51 \%$, although it is reduced in births from people with certain chemical exposures. Therefore, the sex ratio has been suggested as a sentinel environmental health indicator for populations. Trends of declining sex ratio have been reported in some countries, but not others.

What does this study add?

Examining nearly 15 million births over 37 years in the diverse California population, we find an overall trend of declining male births, but diverging trends among different race/ethnic groups. This suggests that the decline in the total population has more to do with changing demographics than environmental factors.

Furthermore, the observed overall decline does not take into account the effect of the increase in Hispanic births. That different racial groups show different "baseline" sex ratios is apparent in figure 4, and in the regression coefficients of the racial groups relative to the white groups (table 2 ). The California Chinese male proportion is slightly higher, and black lower, than the white population, consistent with the findings of others. ${ }^{12}{ }^{15}$ Although the reason for this is not known, it has been suggested to result from differences between races in maternal gonadotropin levels. ${ }^{33}$ The standardised male proportion for Native Americans and the Hispanic white subgroup in California were also lower than the non-Hispanic white subgroup, to our knowledge never before reported. Because Hispanics have a lower sex ratio than the non-Hispanic white population, as the proportion of Hispanic births increased, the overall male birth proportion decreased. As a simple illustration, the adjusted male proportion for the non-Hispanic white subgroup (fig 5) is about 0.514 , and for the Hispanic white subgroup 0.510. In $1982,42 \%$ of white births were Hispanic, $58 \%$ non-Hispanic, for a weighted average of 0.512. By 1996, the proportions were reversed: $63 \%$ were Hispanic, $37 \%$ non-Hispanic, for a weighted average of 0.511. Thus the evidence from 1982 onward suggest that the declining male proportion observed in the combined white population over the entire period may be the result of a proportional increase in Hispanic births during this period.

Previous studies have shown changes in the birth ratio associated with parent's age and birth order. Generally, others have reported a decline in male births with increasing fathers' age, with less clear data on mothers' age. ${ }^{12} 141522{ }^{32} \mathrm{In}$ our data, older fathers (controlling for maternal age) were also associated with decreased male births, but older mothers (adjusted for paternal age) were associated with increasing male births. For birth order, controlling for parents' ages, we find decreasing male births with higher birth order, consistent with some, ${ }^{12} 22$ but not others. ${ }^{33}$

The decline in male birth proportion in California over the past 30 years seems attributable to the changing ethnic composition, and therefore less likely to be attributable to widespread exposures to hormonally active environmental exposures. Furthermore, recent theories propose that exposures may produce specific hormonal effects in men and women leading to opposite results on the sex ratio of their offspring, ${ }^{34}$ so that exposures to both men and women in a population may have effects on the sex ratio that cancel out. Thus, the sex ratio may be useful in situations of high exposures to specific same sex groups (such as in an occupational study), but not as a sentinel indicator in populations. In any case, this study has reinforced the need

\section{Policy implications}

The ratio of males to females is known to be reduced in births from people with certain chemical exposures. Therefore, the sex ratio has been suggested as a sentinel environmental health indicator for populations. Trends of declining sex ratio have been reported in some countries, but not others. Our study's results suggest that changes seen in some populations may have more to do with changing demographics (such as age of parents and race) than environmental factors.

for careful control of demographic factors (such as age of parents and race) to examine small changes in the sex ratio.

\section{ACKNOWLEDGEMENTS}

We thank Barbara Hopkins for assistance with compiling the birth files.

\section{Authors' affiliations}

D Smith, J Von Behren, California Department of Health Services,

Environmental Health Investigations Branch, California, USA

Funding: none.

Competing interests: none declared.

Ethics review: because this was a records based analysis, using existing data that contained no personal identifiers and requiring no human subject contact, neither an ethics review nor informed consent of the subjects was needed.

\section{REFERENCES}

1 Davis DL, Gottleib MB, Stampnitzky JR. Reduced ratio of male to female births in several industrial countries - a sentinel health indicator? JAMA 1998;279:1018-23.

2 Rothwell CJ, Hamilton CB, Leaverton PE. Identification of sentinel health events as indicators of environmental contamination. Environ Health Perspect 1991; 94:261-3.

3 Grech V, Savona-Ventura C, Vassallo-Agius P. Unexplained differences in sex ratios at birth in Europe and North America. BMJ 2002;324:1010-11.

4 del Rio Gomez I, Marshall T, Tsai P, et al. Number of boys born to men exposed to polychlorinated biphenyls. Lancet 2002;360:143-4.

5 Mocarelli P, Gerthoux PM, Ferrari E, et al. Paternal concentrations of dioxin and sex ratio of offspring. Lancet 2000;355:1858-63.

6 Sakamoto M, Nakano A, Akagi H. Declining Minamata male birth ratio associated with increased male fetal death due to heavy methylmercury pollution. Environ Res A 2001;87:92-98.

7 Figa-Talamanca I, Petrelli G. Reduction in male births among workers exposed to metal fumes. Int J Epidemiol 2000;29:381.

8 Goldsmith JR, Potashnik G, Israeli R. Reproductive outcomes in families of DBCP-exposed men. Arch Environ Health 1984;39:85-9.

9 Whorton D, Haas J, Trent L. Reproductive effects of inorganic borates on male employees: birth rate assessment. Environ Health Perspect 1994; 102:129-32.

10 Schnorr TM, Lawson CC, Whelan EA, et al. Spontaneous abortion, sex ratio, and paternal occupational exposure to 2,3,7,8-tetrachlorodibenzo-p-dioxin. Environ Health Perspect 2001; 109:1127-32

11 Karmaus W, Huang S, Cameron L. Parental concentration of dichlorodiphenyl dichloroethene and polychlorinated biphenyls in Michigan fish eaters and sex ration of offspring. J Occup Environ Med 2002;44:8-13.

12 James WH. The human sex ratio. Part 1: a review of the literature. Human Biol 1987;59:721-52.

13 Marcus M, Kiely J, Xu F, et al. Changing sex ratio in the United States, 19691995. Fertil Steril 1998;70:270-3.

14 James WH, Rostron J. Parental age, parity, and sex ratio in births in England and Wales, 1968-1977. J Biosoc Sci 1985;17:47-56

15 Nicolich MJ, Huebner WH, Schnatter AR. Influence of parental and biological factors on the male birth fraction in the United States: an analysis of birth certificate data from 1964 through 1988. Fertil Steril 2000;73:487-92.

16 Mizuno R. The male/female ratio of fetal deaths and births in Japan. Lancet 2000;356:738-9.

17 Graffelman J, Hoekstra RF. A statistical analysis of the effect of warfare on the human secondary sex ratio. Hum Biol 2000;72:433-45.

18 Lancaster PAL, Day PL. Declines in population sex ratios at birth. JAMA 1998;280:1139-40.

19 Martuzzi M, Di Tanno N, Bertollini R. Declining trends of male proportion at birth in Europe. Arch Environ Health 2001;56:358-64.

20 Ulizzi L, Zonta LA. Factors affecting the sex ratio in humans: multivariate analysis of the Italian population. Human Biol 1995;67:59-67.

21 Moller $\mathrm{H}$. Change in male:female ratio among newborn infants in Denmark. Lancet 1996;348:828-9. 
22 Vartiainen T, Kartovaara L, Tuomisto J. Environmental chemicals and changes in sex ratio: analysis over 250 years in Finland. Environ Health Perspect 1999; 107:813-15.

23 Catalano RA. Sex ratios in the two Germanies: a test of the economic stress hypothesis. Hum Reprod 2003;18:1972-1975.

24 Jongbloet PH, Zielhuis GA, Groenwoud HMM, et al. The secular trend in male:female ratio at birth in postwar industrialized countries. Environ Health Perspect 2001;109:749-52.

25 James WH. Offspring sex ratios as an index of pollution hazard in residential environments. Occup Environ Med 1995:52.556.

26 Baumeister L, Marchi K, Pearl M, et al. The validity of information on "race" and "Hispanic ethnicity" in California birth certificate data. Health Serv Res 2000;35:869-83.

27 Wacholder S. Binomial regression in GLIM: estimating risk ratios and risk differences. Am J Epidemiol 1986;123:174-84.
28 Greenland S. Dose-response and trend analysis in epidemiology: alternatives to categorical analysis. Epidemiology 1995;6:356-65

29 McCullagh P, Nelder JA. Generalized linear models. 2nd ed. London: Chapman and Hall, 1989:90-119.

30 Lane PW, Nelder JA. Analysis of covariance and standardisation as instances of prediction. Biometrics 1982;38:613-21.

31 Armitage P, Berry G, Matthews JNS. Statistical methods in medical research. 4th ed. Oxford: Blackwell Science, 2002:289-92.

32 James WH. The human sex ratio. Part 2: a hypothesis and a program of research. Human Biol 1987;59:873-900.

33 Jacobsen R, Moller H, Mouritsen A. Natural variation in the human sex ratio Hum Reprod 1999; 14:3120-5.

34 James WH. Sex ratios at birth as monitors of endocrine disruption. Environ Health Perspect 2001;109:A250.

\section{THE JECH GALLERY}

\section{Guinness Record Healthy Breakfast day to promote healthy eating}

B reakfast plays an important part in mproving overall nutritional status, and improving feeling of health and wellbeing. ${ }^{1}$ The nutritional, educational, and economic value of having breakfast is increasingly evident. A territory-wide Healthy Breakfast Programme with participation of 91519 people in 144 venues was launched by the Centre for Health Education and Health Promotion of the Chinese University of Hong Kong in 2002 to promote regular healthy breakfast eating. ${ }^{2}$ The unique feature is the involvement of celebrities such as pop stars, media, politicians, senior academic so it can facilitate community participation and promote participant and community empowerment. The programme used the community organisation model, which is a planned process to activate a community using its own social structures and any available resources to accomplish goals consistent with local values. ${ }^{3}$ This event was the largest healthy breakfast programme breaking the Guinness Record.

Albert Lee

Chinese University of Hong Kong, Department of Community and Family Medicine, Faculty of Medicine 4th Floor, School of Public Health,

Prince of Wales Hospital Shatin, NT, Hong Kong; alee@cuhk.edu.hk

\section{REFERENCES}

1 Nicklas N, Bao W, Webber L, et al. Breakfast consumption affects adequacy of total daily intake in children. J Am Diet Assoc 1993;93:886-91.

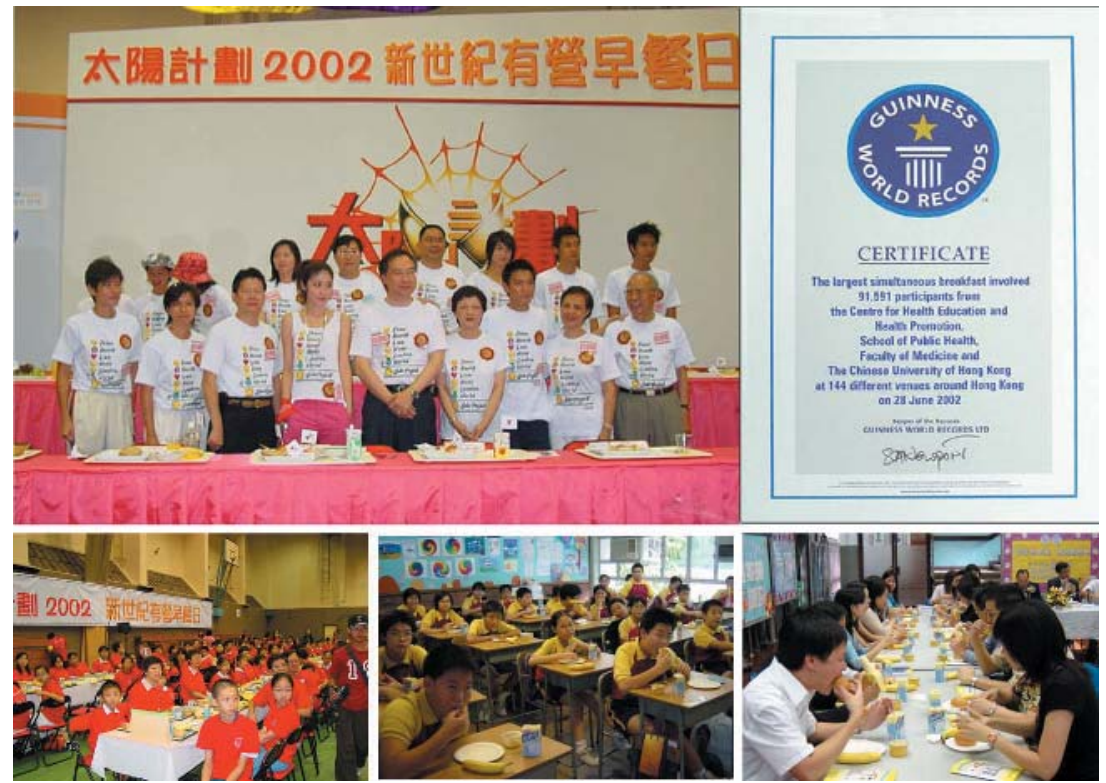

Top: celebrities including pop stars, public figures, sports stars, senior academics had breakfast simultaneously with 91519 participants in 144 different venues. Bottom left: students representing different schools at the university campus. Middle: students eating their healthy breakfast at their school. Bottom right: staff and witnesses ate the healthy breakfast together at school.

2 Lee A, Tsang CKK, Tso CY, et al. Healthy Breakfast Campaign: Guinness Record. Journal of Primary Care and Health Promotion 2004:1:10-16.

3 Bracht N. Health promotion at the community level: new advances. 2nd ed. California: Sage, 1999:86. 